\title{
DOAÇÃO E TRANSPLANTE DE ÓRGÃOS NA CONCEPÇÃO BIOÉTICA: uma revisão integrativa
}

\author{
Isabelle Ramalho FERREIRA ${ }^{1}$ \\ Patrick Leonardo Nogueira da SILVA ${ }^{2}$ \\ Wilson AGUIAR FILHO ${ }^{3}$ \\ Renata Patrícia Fonseca GONÇALVES ${ }^{4}$ \\ Simone Guimarães Teixeira SOUTO ${ }^{5}$ \\ Valdira Vieira de OLIVEIRA ${ }^{6}$
}

\begin{abstract}
${ }^{1}$ Acadêmica de Odontologia, Universidade Estadual de Montes Claros/UNIMONTES, Montes Claros (MG), Brasil. E-mail: isabelle.ramalho@hotmail.com

${ }^{2}$ Enfermeiro, Especialista em Saúde da Família e Didática e Metodologia do Ensino Superior, Universidade Estadual de Montes Claros/UNIMONTES, Montes Claros (MG), Brasil. E-mail: patrick_mocesp70@ hotmail.com

${ }^{3}$ Enfermeiro, Mestre em Saúde Pública, Escola Nacional de Saúde Pública Sérgio Arouca/ENSP/FIOCRUZ, Rio de Janeiro (RJ), Brasil. E-mail: aguiar.wilson@gmail.com

${ }^{4}$ Enfermeira, Mestre e Doutoranda em Enfermagem, Professora do Departamento de Enfermagem da Universidade Estadual de Montes Claros/UNIMONTES, Montes Claros (MG), Brasil. E-mail: renatapfonseca@ yahoo.com.br

${ }_{5}^{5}$ Enfermeira, Mestre em Ciências da Saúde, Professora do Departamento de Enfermagem da Universidade Estadual de Montes Claros/UNIMONTES, Montes Claros (MG), Brasil. E-mail: simonegts28@ yahoo.com.br

${ }^{6}$ Enfermeira, Mestre em Ciências da Saúde, Professora do Departamento de Enfermagem da Universidade Estadual de Montes Claros/UNIMONTES, Montes Claros (MG), Brasil. E-mail: valdira_oliver@ hotmail.com
\end{abstract}

Recebido em: 20/12/2014 - Aprovado em: 04/06/2015 - Disponibilizado em: 15/07/15

\begin{abstract}
RESUMO
Introdução: como em muitas outras áreas, o Brasil apresenta enormes disparidades nas estatísticas de doações e transplantes de órgãos. Enquanto alguns estados há anos alcançam números comparáveis aos melhores no mundo, outros chegam ao final do ano sem realizar um transplante sequer. Objetivo: identificar os principais indicadores de resultado do processo de doação e transplantes de órgãos no Brasil. Método: trata-se de um estudo de natureza descritiva do tipo revisão integrativa da literatura realizada na rede da Biblioteca Virtual da Saúde. Foram utilizados os descritores: bioética; transplante de órgãos; família e; obtenção de tecidos e órgãos. Resultados: estudos levantados descrevem o ato de doação de órgãos relacionando-o ao estado emocional e familiar; os aspectos geradores de sofrimento e alívio no processo da aceitação do ente querido ter falecido e a possibilidade da doação dos seus órgãos; os conflitos de interesses profissionais e a abordagem aos familiares; os fatores facilitadores e os impeditivos para doação de órgãos. Considerações finais: é primordial ressaltar a responsabilidade e a compreensão de que, eticamente, doar é uma opção generosa, um gesto de amor para com o próximo, que expressa solidariedade humana.

Palavras-chave: Bioética. Família. Transplante de órgãos.

\section{DONATION AND TRANSPLANTATION OF ORGANS IN BIOETHICS DESIGN: an integrative review}

\begin{abstract}
Introduction: as in many other areas, Brazil has huge disparities in the statistics of organ donations and transplants. While some states for years reach numbers comparable to the best in the world, others reach the end of the year without performing a transplant even. Objective: to identify the key outcome indicators associated with blood donation and organ transplants in Brazil. Method: this is a study of descriptive type integrative literature review performed in the access of the Virtual Health Library network. The following parameters were used: bioethics; organ transplantation; family; and obtaining tissues and organs. Results: studies describe the act of organ donation relating to the emotional and family status; generators aspects of pain and pleasure in the process of accepting the loved one has passed away and the possibility of donating their organs; conflicts of interests and professional approach to family; facilitators and the impeding factors for 190

Revista da Universidade Vale do Rio Verde, Três Corações, v. 13, n. 1, p. 190-203, 2015
\end{abstract}


organ donation. Final considerations: it is important to emphasize the responsibility of strengthening the understanding that, ethically, is donating a generous option, a gesture of love towards the neighbor, and an expression of human solidarity.

Key words: Bioethics. Family. Organ transplantation.

\section{INTRODUÇÃO}

Desde tempos antigos, a possibilidade de substituir órgãos doentes por outros sadios sempre deslumbrou a humanidade. Depois de uma longa história de fracassos, o transplante de órgãos e tecidos passou a ser aceito como método terapêutico lídimo graças aos avanços das técnicas cirúrgicas e à introdução de fármacos imunomoduladores (ROCHA, 2010).

O transplante permitiu manter com vida um grande número de pessoas vítimas de doenças que outrora não tinham possibilidade de sobreviver aos episódios de agudização (SANTOS, 1998). Para o desenvolvimento técnico-científico dos transplantes e o consequente sucesso dessa modalidade terapêutica, é necessária a obtenção de órgãos. $\mathrm{O}$ incremento da realização de transplantes acarretou, além da cura de pacientes anteriormente desenganados, a valorização do ser humano como reserva de órgãos e tecidos, suscitando objeções bioéticas e jurídicas em razão da inviolabilidade e inalienabilidade do corpo, as quais moldaram a normatização de condutas capazes de equilibrar um caráter aceitável de rompimento da integridade do corpo humano com a possibilidade de remoção se estruturas para fins terapêuticos (ROCHA, 2010; SANTOS, 1998).

Embora o número de transplantes tenha aumentado, a escassez de órgãos continua sendo um dos maiores obstáculos às equipes transplantadoras em todos os países, pois a demanda por transplantes vem aumentando em escala maior que as doações, fazendo com que as listas de espera se ampliem (CAMPOS, 2001). Quanto à forma de obtenção dos órgãos e tecidos, especificamente falando em órgãos oriundos de seres humanos, a questão mais importante é a do resguardo da voluntariedade e da espontaneidade no ato de doar, ou se aceita que o bem comum está acima da vontade do indivíduo e se permite a apropriação dos órgãos de cadáveres ou se delibera que o indivíduo é proprietário do seu corpo e, desta forma, pode dispor dele com o melhor lhe aprouver (SANTOS, 1998; CAMPOS, 2001).

O tipo de procedimento também apresenta inúmeros questionamentos. Os transplantes de órgãos internos foram os primeiros, mas já foram realizados alguns com partes externa do corpo, como o transplante de mão e mais recentemente o transplante parcial de face.

A obtenção de órgãos de doador vivo 
tem sido muito utilizada, ainda é útil, porém é igualmente questionável desde o ponto de vista ético. No Brasil este tipo de doação somente tem sido aceito quando existe relação de parentesco entre doador e receptor. A doação de órgãos por parte de amigos ou até mesmo de desconhecidos tem sido fortemente evitada. As questões envolvidas são a autonomia e a liberdade do doador ao dar seu consentimento e a avaliação de risco/benefício associada ao procedimento, especialmente com relação à não-maleficência (mutilação) do doador (SANTOS, 1998).

As transformações da década de sessenta, especialmente nos contextos sociopolítico e tecnológico, impulsionaram o nascimento da bioética, que se origina para relacionar os avanços tecnológicos e a qualidade/condição da vida. Desta forma, a bioética seria uma forma de trazer "limite" aos avanços técnico-científicos para preservar a vida no planeta. Em 1971, Potter propõe a constituição de uma ética aplicada à situação de vida, compreendendo que este seria o caminho à sobrevivência da espécie humana. Considera que, para garantir a sobrevivência da espécie, seria preciso respeito aos valores humanos, pressupondo prudência na relação entre $\mathrm{o}$ conhecimento biológico e os valores humanos (DINIZ; GUILHEM, 2002).

As novas práticas de atenção à saúde são cada vez mais exercidas por equipes de profissionais, pressupondo a integração dos mesmos em um fazer comum. Neste contexto a bioética se depara com dilemas oriundos do exercício destes profissionais estimulando o diálogo interdisciplinar, de colaboração e interação de diferentes áreas de conhecimento. Os avanços biotécnicos modificaram o paradigma do conhecido de morte, enquanto acontecimento pontual decorrente da parada simultânea da consciência, respiração, batimentos cardíacos, circulação e falência de outros órgãos, para o de morte encefálica, quando há constatação de coma não reativo, apneia, abolição de reflexos do tronco encefálico e os espinhais. Apesar destas restrições, o entusiasmo com resultados recentes dos transplantes fez com que os olhos da comunidade científica internacional, e a brasileira em especial, se voltassem para os fetos anencéfalos, que poderiam suprir e sempre alegada escassez de órgãos de dimensões apropriadas para o atendimento de neonatos (SANTOS, 1998; CAMPOS, 2001; DINIZ; GUILEM, 2002).

As possibilidades morais, legais e práticas de se usar o anencéfalo como fonte de órgãos e tecidos para transplante é tão restritas que acabam por desestimular as pesquisas científicas e a ocorrência de doações nesse sentido (ROCHA, 2010). Os profissionais que lidam com famílias que demonstram interesse em doar órgãos têm papel relevante em sua 
obtenção. Esse papel pode ser confirmado na atuação da Organização Nacional de Transplantes da Espanha, que apresenta o maior número de doadores por milhão de habitantes do mundo. Tão grande êxito foi possível apoiando-se na função dos coordenadores de transplantes, que são profissionais treinados para a detecção dos doadores e com habilidades para manejar o complexo processo de doação de órgãos (LIMA, 2012).

Portanto, o estudo objetiva identificar os principais indicadores de resultado do processo de doação e transplantes de órgãos no Brasil mediante revisão integrativa da literatura.

\section{MATERIAL E MÉTODO}

Trata-se de um estudo com análise descritiva do tipo revisão integrativa da literatura, que, segundo Mendes, Silveira e Galvão (2008) é um método de pesquisa que permite a busca, a avaliação crítica e a síntese das evidências disponíveis quanto ao tema estudado, de forma a ter como produto final o estado atual do conhecimento investigado e a identificação de lacunas que direcionam para o desenvolvimento de pesquisas futuras.

O levantamento bibliográfico foi realizado na rede de acesso da Biblioteca Virtual da Saúde (BVS) na qual o período da coleta dos artigos compreendeu os meses de setembro a outubro de 2013. Os mesmos foram selecionados nas seguintes bases de dados eletrônicas: Scientific Electronic Library Online (SciELO), Literatura Latino-Americana e do Caribe em Ciências de Saúde (Lilacs) e Base de Dados de Enfermagem (BDENF). Foram utilizados os seguintes descritores: "Bioética"; "Transplante de órgãos"; "Família" e; “Obtenção de tecidos e órgãos".

Para levantar os artigos foram considerados os seguintes critérios de inclusão: estudos na íntegra, no idioma português, no período de 2005 a 2013 e que respondessem à questão norteadora da pesquisa: Quais os principais indicadores de resultado do processo de doação e transplantes de órgãos no Brasil?

$\mathrm{Na}$ busca inicial foram encontradas 30 publicações nas bases de dados SciELO, Lilacs e BDENF. Dessas, 22 foram excluídas e oito foram selecionadas por atenderem aos critérios de inclusão propostos, de forma a constituir a amostra deste estudo (Tabela 1). 
Tabela 1 - Distribuição dos artigos encontrados e selecionados Base de dados da Biblioteca Virtual de Saúde (BVS).

\begin{tabular}{cccc}
\hline Base de dados & Publicações encontradas & Publicações excluídas & Publicações selecionadas \\
\hline SciELO & 11 & 06 & 05 \\
Lilacs & 13 & 12 & 01 \\
BDEnf & 06 & 04 & 02 \\
Total & $\mathbf{3 0}$ & $\mathbf{2 2}$ & $\mathbf{0 8}$ \\
\hline
\end{tabular}

Fonte: Pesquisa Unimontes, Montes Claros/MG; 2014. 
Tabela 2 - Distribuição dos artigos selecionados segundo título, periódico, local, autor(es), ano, objetivo(s), metodologia e conclusões (2005-2013). Montes Claros (MG), 2014.

\begin{tabular}{|c|c|c|c|c|c|c|c|}
\hline $\mathbf{n}^{\mathbf{0}}$ & Título & Periódico & Local & Autor (Ano) & Objetivo & Metodologia & Conclusões/Considerações finais \\
\hline 1 & $\begin{array}{l}\text { Bioética e doação } \\
\text { de órgãos no } \\
\text { Brasil: aspectos } \\
\text { éticos abordagem } \\
\text { à família do } \\
\text { potencial doador. }\end{array}$ & $\begin{array}{l}\text { Revista } \\
\text { Bioética }\end{array}$ & Brasília & $\begin{array}{c}\text { Pessalacia, } \\
\text { Cortes e } \\
\text { Ottoni }(2011)\end{array}$ & $\begin{array}{lr}\text { Descrever } & \text { as } \\
\text { questões éticas que } \\
\text { poça influenciar } \\
\text { nas taxas de } \\
\text { consentimento de } \\
\text { familiares } \\
\text { relação à doação } \\
\text { de órgãos. }\end{array}$ & $\begin{array}{l}\text { Artigo original } \\
\text { de análise } \\
\text { descritiva. }\end{array}$ & $\begin{array}{l}\text { A doação de órgãos é um ato complexo que } \\
\text { gira em torno da revelação da morte cerebral } \\
\text { do cliente aos familiares até o ato da } \\
\text { retirada. Sendo regularizado por leis. } \\
\text { Verifica-se um grau de dificuldade em } \\
\text { aceitação a morte para assim a ação de doar } \\
\text { órgãos e tecidos do falecido. }\end{array}$ \\
\hline 2 & $\begin{array}{l}\text { Doação de órgãos } \\
\text { e tecidos: relação } \\
\text { com o corpo em } \\
\text { nossa } \\
\text { Sociedade. }\end{array}$ & $\begin{array}{c}\text { Acta Paulista } \\
\text { de } \\
\text { Enfermagem }\end{array}$ & $\begin{array}{c}\text { São } \\
\text { Paulo }\end{array}$ & $\begin{array}{c}\text { Roza et al. } \\
\text { (2010) }\end{array}$ & $\begin{array}{l}\text { Objetiva } \\
\text { considerações } \\
\text { teóricas tecer } \\
\text { doação de órgãos e } \\
\text { tecidos e } \\
\text { relação com } \text { sua } \\
\text { corpo em nossa } \\
\text { sociedade. }\end{array}$ & $\begin{array}{l}\text { Artigo de } \\
\text { revisão de } \\
\text { análise } \\
\text { descritiva. }\end{array}$ & $\begin{array}{l}\text { O tema, transplantes de órgãos, certamente, } \\
\text { tem características que o diferenciam de } \\
\text { qualquer outra questão de saúde. Assim, } \\
\text { verifica-se que a taxa de doação depende de } \\
\text { um olhar ampliado além das questões } \\
\text { técnicas do processo de doação de órgãos e } \\
\text { tecidos. }\end{array}$ \\
\hline 3 & $\begin{array}{l}\text { Doação de órgãos } \\
\text { para transplante: } \\
\text { conflitos éticos } \\
\text { na percepção do } \\
\text { profissional }\end{array}$ & $\begin{array}{l}\text { O Mundo da } \\
\text { Saúde }\end{array}$ & $\begin{array}{c}\text { São } \\
\text { Paulo }\end{array}$ & Lima (2012) & $\begin{array}{l}\text { Discorrer sobre os } \\
\text { conflitos éticos no } \\
\text { processo de } \\
\text { doação de órgão } \\
\text { para transplante a } \\
\text { partir } \\
\text { perspectiva da } \\
\text { profissional } \\
\text { enfermeiro. }\end{array}$ & $\begin{array}{l}\text { Artigo de } \\
\text { revisão de } \\
\text { análise } \\
\text { descritiva. }\end{array}$ & $\begin{array}{l}\text { Os profissionais que vivenciam os conflitos } \\
\text { existenciais e morais no processo de doação } \\
\text { de órgãos necessitam resignificar o sentido } \\
\text { do seu trabalho, por meio de um processo de } \\
\text { autoconhecimento para saber lidar com o } \\
\text { significado da morte, sofrimento e a dor da } \\
\text { perda. }\end{array}$ \\
\hline 4 & $\begin{array}{l}\text { O anencéfalo } \\
\text { como doador de } \\
\text { órgãos e tecidos } \\
\text { para transplantes: } \\
\text { possibilidades }\end{array}$ & $\begin{array}{c}\text { Revista } \\
\text { Brasileira de } \\
\text { Saúde Materna }\end{array}$ & Recife & Rocha (2010) & $\begin{array}{l}\text { Descrever sobre a } \\
\text { possibilidade do } \\
\text { uso de órgãos e } \\
\text { tecidos } \\
\text { portadores } \\
\end{array}$ & $\begin{array}{l}\text { Artigo original } \\
\text { de análise } \\
\text { descritiva. }\end{array}$ & $\begin{array}{l}\text { As possibilidades éticas de se usar o } \\
\text { anencéfalo como fonte de órgãos e tecidos } \\
\text { para transplante são tão restritas que acabam } \\
\text { por desestimular as pesquisas científicas e a } \\
\text { ocorrência de doações neste sentido, algo }\end{array}$ \\
\hline
\end{tabular}


legais, morais e

práticas. anencefalia,

ressaltando os

aspectos morais

legais e práticos.

Avaliar o desafio

médico, jurídico e

ético conferido

pela anencefalia ao

debate sobre a

Crianças

anencefálicas e

5 doações de

órgãos: questões

legais e éticas no

Brasil

\section{Saúde, Ética \& São Sarvalho e Justiça. \\ Paulo \\ Miziara}

(2012) utilização de

órgãos

provenientes de

neonatos

anencéfalos para fins de transplante

sob o ponto de

vista bioético no

Brasil.

Desvelar

doação de

6 percepção

\section{de}

de

Americana de

Enfermagem órgãos:

familiares

doadores

cadáveres

\section{São}

Paulo
Santos e

$$
\text { (2005) }
$$

familiares

doadores

cadáveres sobre o

processo doação de órgãos

\begin{tabular}{|c|c|c|c|c|c|}
\hline $\begin{array}{l}\text {.Doação } \\
\text { órgãos: } \\
\text { compreensão } \\
\text { perspectiva } \\
\text { adolescentes }\end{array}$ & $\begin{array}{l}\text { na } \\
\text { de }\end{array}$ & $\begin{array}{l}\text { Revista } \\
\text { Brasileira de } \\
\text { Saúde } \\
\text { Materno- } \\
\text { Infantil }\end{array}$ & Recife & $\begin{array}{c}\text { Monteiro et } \\
\text { al. (2011) }\end{array}$ & $\begin{array}{l}\text { Conhecer a } \\
\text { perspectiva dos } \\
\text { adolescentes sobre } \\
\text { doação de órgãos }\end{array}$ \\
\hline
\end{tabular}
para transplante. que tem despertado sua revisão na tentativa de produzir reconsiderações liberais. satisfação dos critérios de morte do tronco

Artigo de cerebral, não se consegue obter órgãos que revisão de sejam viáveis para transplantes, mesmo com análise suporte de terapia intensiva. Cientes de que descritivo- toda problemática apontada não será exploratória facilmente solucionada, apenas tenta-se, a partir da dissertação, contribuir para o debate em torno de tal tópico.
A ótica dos adolescentes, a doação de órgãos

Artigo original é necessária e eles desejam contribuir, de análise porém seus conhecimentos são inadequados. descritivo- Há necessidade de informações sistemáticas exploratório e precisas para tornar realidade seu desejo em doar órgãos e salvar vidas. 
Avaliar a força de músculos

Força muscular e mortalidade na

8 lista de espera de transplante de

Revista Brasileira de Fisioterapia São

Carvalho et respiratórios e de mão em pacientes na lista de espera para o transplante de fígado fígado
Seria importante que o transplante fosse realizado precocemente - antes das Artigo original manifestações da doença, o que dificulta o de análise prognóstico. Existem muitos estudos descritivo- abrangendo prognóstico, estado nutricional, exploratória terapêuticas nutricionais pré-transplante e sobrevida, mas que, devido à escassez de órgãos, proporcionam infinitas discussões.

Fonte: Base de dados da Biblioteca Virtual de Saúde (BVS). 


\section{RESULTADOS E DISCUSSÃO}

Todos os oitos artigos selecionadas atenderam aos critérios de inclusão e estão assim distribuídos: cinco na base SciELO; um na Lilacs e dois na BDEnf. A Tabela 2 apresenta os artigos selecionados, segundo título, periódico, local, autor(es), ano, objetivo(s), metodologia e conclusões do estudo no período de 2008 a 2012. No ano de 2010, 2011 e 2012 houve maior número de publicações (n=6), seguido de uma em 2009 e o mesmo número em 2005. Quanto ao objetivo das publicações, os autores buscaram, em sua maioria, descrever o ato de doação de órgãos relacionados ao estado emocional familiar; os aspectos geradores de sofrimento e prazer no processo da aceitação do ente querido ter falecido e a possibilidade da doação dos seus órgãos; os conflitos de interesses profissionais e a abordagem aos familiares; os fatores facilitadores e os impeditivos para doação de órgãos.

Os artigos selecionados revelaram que as internações ocorrem de forma inesperada e decorrem, principalmente, de causas traumáticas, podendo decorrer, também, de doenças congênitas ou adquiridas. Com a internação, a família é informada da gravidade do quadro clínico e do risco de morte do paciente. Antes mesmo da informação médica, a família, muitas vezes, percebe a seriedade da situação e a proximidade da morte do paciente. A família considera a assistência prestada durante a internação do paciente satisfatória, quando observa que o atendimento é adequado e que os profissionais estão empenhados no tratamento.

Imediatamente após a constatação da morte do paciente, um profissional informa sobre a possibilidade da doação de órgãos, averigua o conhecimento e o preparo da família sobre a questão, explica o processo de doação e aconselha que os familiares sejam consultados para a tomada de decisão. Um dos motivos que contribui para a dificuldade na compreensão e/ou não aceitação do diagnóstico de morte encefálica advém do fato do paciente apresentar batimentos cardíacos, movimentos respiratórios e temperatura corpórea. A família não percebe o paciente como morto e crê na possibilidade de reversão do quadro. Essa esperança, largamente alimentada por narrativas de história oral bem como por filmes e novelas, torna-se ainda mais arraigada quando o paciente é criança, cuja morte é mais difícil conceber e aceitar.

Um aspecto importante a ser considerado na definição de morte são as várias nuances que envolvem todo o processo de morrer. É fato que familiares e pessoas leigas questionam os critérios de definição de morte encefálica. Embora a mesma seja caracterizada como morte clínica, para os familiares ela só é evidenciada pela parada cardiopulmonar. A morte individual do 
cérebro não faz com que os indivíduos a encarem como morte, pois o coração continua batendo e dá a impressão de que o indivíduo está apenas dormindo. Infelizmente, essa situação dificulta a distinção entre a vida e a morte e provoca intensa emoção e ansiedade para a família (PESSALACIA; CORTES; OTTONI, 2011).

A assistência dispensada ao paciente e à família também influi na decisão quanto à doação de órgãos. Estudo apontou como fatores determinantes para a doação de órgãos, pela família, questões socioculturais tais como: etnia, crenças religiosas, nível socioeconômico e informação sobre a doação e transplantes, conhecimento do status de doador do morto, experiência prévia da família com doação ou transplante bem como e campanhas educacionais. Além destes fatores de cunho geral contribuem também aqueles mais relacionados aos profissionais e à forma como é prestado o serviço: credibilidade no sistema de transplante e distribuição de órgãos; grau de satisfação com o atendimento médico e com as explicações acerca da morte encefálica; condições e momento de abordagem da família; grau de treinamento do entrevistador; explicações sobre custos e funeral e; legislação de consentimento presumido (SANTOS; MASSAROLLO, 2005).

Não há como negar que o processo de doação é burocrático, desorganizado, demorado, desgastante e cansativo. Quanto à liberação do corpo, a família é informada sobre a possibilidade de atrasos e intercorrências na realização dos exames para o diagnóstico de morte encefálica, sobre o tempo de cirurgia necessário para a extração dos órgãos e sobre o encaminhamento do corpo ao Instituto Médico Legal (IML), nos casos de morte traumática. Há famílias, entretanto, que não consideram a liberação do corpo complicada, entendendo a demora como normal e decorrente da burocracia existente.

Embora a situação vivenciada seja sofrida e estressante, não há arrependimento quanto à doação dos órgãos, havendo, inclusive, a crença de que, se ocorrer novamente a situação, a família concordará com a doação. São mencionados como fatores dificultadores do processo de doação a não compreensão do conceito de morte encefálica, $\mathrm{o}$ aspecto religioso envolvido e a demora na liberação do corpo pelo IML (SANTOS; MASSAROLLO, 2005).

Segundo as diretrizes básicas para a captação e retirada de múltiplos órgãos e tecidos da Associação Brasileira de Transplante de Órgãos (ABTO), o sucesso da entrevista familiar depende basicamente de três fatores: predisposição à doação, qualidade do atendimento hospitalar recebido, habilidade e conhecimento do entrevistador (BRASIL, 2009). Além do disso, destaca-se ainda que as condições para a entrevista familiar envolvam vasta compreensão, por 
parte do entrevistador, da situação que a família está vivenciando, na qual, em período difícil como o luto, terá que decidir pela doação dos órgãos de seu ente querido ciente de que a mesma poderá repercutir em nova vida para outro indivíduo. Outras condições importantes da entrevista envolvem a conversa com o médico que assistiu ao paciente, a identificação da melhor pessoa para oferecer a opção de doação e, ainda, ambiente tranquilo e confortável.

A família deve também saber que a responsabilidade não precisa ser dada no exato momento da entrevista, que pode se reunir e discutir o assunto a fim de obter a melhor decisão. Essa decisão deve ser respeitada, seja qual for. Não é recomendável tentar convencer os familiares sobre o bem da doação ou tentar influenciá-los com argumentos religiosos ou morais. Expor estatísticas não apresenta qualquer validade neste momento. $\mathrm{O}$ entrevistador deve explicar que alguns órgãos podem não ser doados e orientar que a decisão de doação pode ser revogada a qualquer momento, mesmo após a assinatura do termo de consentimento. A literatura registra que explicar pontos específicos pode estar associado a maior taxa de consentimento, aspecto também relacionado ao tempo que o entrevistador passa com a família (ROZA et al., 2012; BRASIL, 2009).

A morte é um consentimento biológico que encerra uma vida, sendo capaz de suscitar nos indivíduos que a vivenciam e naqueles que estão à sua volta intensas reações emocionais. Morrer é um processo inexorável, que expõe a nossa condição humana de vulnerabilidade e caracteriza tanto o que temos de universal quanto o que nos é singular. Atualmente, encara-se o morrer como um processo construído socialmente, que não se distingue das outras dimensões do universo das relações sociais. Sendo assim, está presente em nosso cotidiano e, independente de suas causas ou formas, seu grande palco continua sendo os hospitais e instituições de saúde. Por isso, a morte ainda pode ser considerada como algo institucionalizado e medicalizado, principalmente hoje, quando os hospitais possuem aparelhos com alta tecnologia que permitem a manutenção do corpo do paciente em funcionamento, independentemente da condição de qualidade de vida.

No Brasil, o termo morte encefálica foi oficialmente aceito a partir da publicação da Resolução 1.346/91 do Conselho Federal de Medicina (CFM), atualizada pela Resolução 1.480/97, que propõe uma mescla de protocolos, destacando-se como critérios clínicos o coma profundo não reativo e imperceptível, apneia, midríase paralítica bilateral e o reflexo óculo motor ausente. Esses parâmetros devem ser mantidos inalterados por período superior a seis horas, além da obrigatoriedade da realização de testes de confirmação. Só então poderá 
considerar o indivíduo como potencial doador de órgãos e tecidos (BRASIL, 1997).

Segundo preconiza esta resolução, o potencial doador deverá ser submetido a uma avaliação clínica e a um exame complementar por dois médicos não participantes das equipes de transplante, e pelo menos um deles deverá ser neurologista, neurocirurgião ou neuropediatra com título de especialista devidamente registrado. Portanto, a morte encefálica pode ser caracterizada pela perda definitiva e irreversível das funções do encéfalo (hemisférios cerebrais e tronco cerebral), de causa conhecida e determinada de forma inequívoca, sendo que a especificidade do diagnóstico deve ser de 100\% (BRASIL, 1997).

A possibilidade de alegrar pessoas que esperam por um transplante, mediante doação de órgãos, consola e recompensa a família, embora a dor não termine. Há a manifestação do desejo da família de ajudar a incentivar a doação para possibilitar que aqueles que necessitam de um transplante continuem a viver (CARVALHO; MIZIARA, 2012). Adicionalmente, percebe-se que o aumento da taxa de doadores depende de um olhar que extrapole as questões técnicas do processo de doação de órgãos e tecidos. Vários países trabalham sistematicamente nesse processo, há longo tempo, incorporando a abordagem social e a perspectiva ética, baseadas no voluntarismo das famílias e no respeito ao direito de autonomia dos potenciais doadores.
Esta visão precisa ser parte integrante de quem sonha ter neste processo a certeza de desenvolver um trabalho justo e benéfico à comunidade. Além da priorização no contexto sanitário brasileiro, um dos compromissos que se deve esperar do Estado é o estabelecimento de uma legislação adequada, acompanhada de infraestrutura sanitária pertinente que estimule e facilite o controle de todo o conjunto de um novo Sistema Nacional de Transplante. Desse modo, o grande desafio para o profissional que trabalha com captação de órgãos e tecidos é ter competência ética, para garantir a melhoria contínua desse processo, dando ênfase à comunicação adequada entre a equipe e os familiares, além de investir em processos de trabalho que identifiquem questões cotidianas que tornam a assistência prestada impessoal e rude. Por fim, incorporar nas campanhas de doação de órgãos e tecidos, familiares de doadores falecidos e suas experiências (ROZA et al., 2010).

\section{CONSIDERAÇÕES FINAIS}

A alocação dos órgãos para transplante deve ser feita em dois estágios, o primeiro deve ser realizado pela própria equipe de saúde, contemplando os critérios de elegibilidade, de probabilidade de sucesso e de progresso à ciência, visando à beneficência ampla. O segundo estágio, a ser realizada por um Comitê de Bioética, pode utilizar os 
critérios de igualdade de acesso, das probabilidades estatísticas envolvidas no caso, da necessidade de tratamento futuro, do valor social do indivíduo receptor, da dependência de outras pessoas, entre outros critérios.

Para a Equipe de Saúde trabalhar com o transplante de órgãos deve ser, e é considerado gratificante, além de poder ajudar a salvar vidas o mesmo proporciona maiores oportunidades no campo de trabalho e desenvolvimento profissional aumentando seu conhecimento e tendo uma melhor interação com a família do potencial doador. Contudo, é primordial ressaltar a responsabilidade de fortalecer a compreensão de que eticamente, doar é uma opção generosa, um gesto de amor para com o próximo, e uma expressão de solidariedade humana.

Perante o exposto, a Bioética torna-se indispensável ao ser humano nos dias atuais, devido aos constantes e acelerados avanços da Biociência, necessitando contar com uma presença maior da sociedade, para a promoção da reflexão em torno do transplante de órgãos e tecidos, através da qual cada pessoa poderá estabelecer uma postura frente a esta problemática contribuindo para mais estudos e discussões entre a população científica, e sociedade para um conhecimento mais aprofundado sobre esses aspectos.

\section{REFERÊNCIAS}

BRASIL. Associação Brasileira de
Transplante de Órgãos. Diretrizes básicas para captação e retirada de múltiplos órgãos e tecidos da associação brasileira de transplante de órgãos. São Paulo (SP): ABTO; 2009.

BRASIL. Conselho Federal de Medicina. Resolução CFM nº. 1.480/1997. Dispõe sobre a retirada de órgãos, tecidos e partes do corpo humano para fins de transplante e tratamento. Brasília: CFM; 1997.

CAMPOS, H. H. Aumento do número de transplantes e da doação de órgãos e tecidos: processo de construção coletiva. São Paulo (SP): Associação Brasileira de Transplante de Órgãos (ABTO); 2001.

CARVALHO, F. I.; MIZIARA, C. S. M. G. Crianças anencefálicas e doações de órgãos: questões legais e éticas no Brasil. Saúde, Ética \& Justiça. São Paulo (SP), v. 17, n. 1, p. 3-11, 2012.

CARVALHO, E. M. et al. Força muscular e mortalidade na lista de espera de transplante de fígado. Revista Brasileira de Fisioterapia. São Paulo (SP), v. 12, n. 3, p. 235-240, 2008.

DINIZ, D.; GUILHEM, D. O que é bioética? São Paulo (SP): Brasiliense; 2002. 
transplante: conflitos éticos na percepção do profissional. O Mundo da Saúde. São Paulo (SP), v. 36, n. 1, p. 27-33, 2012.

MENDES, K. D. S. et al. Revisão integrativa: método de pesquisa para a incorporação de evidências na saúde e na enfermagem. Texto \& Contexto - Enfermagem. Florianópolis (SC), v. 17, n. 4, p. 758-764, 2008.

MONTEIRO, A. M. C. et al. Doação de órgãos: compreensão na perspectiva de adolescentes. Revista Brasileira de Saúde Materno-Infantil. Recife (PE), v. 11, n. 4, p. 389-396, 2011.

PESSALACIA, J. D. R. et al. Bioética e doação de órgãos no Brasil: aspectos éticos na abordagem à família do potencial doador. Revista Bioética. Brasília (DF), v. 19, n. 3, p. 671-682, 2011.

ROCHA, R. F. O anencéfalo como doador de órgãos e tecidos para transplante: possibilidades legais, morais e práticas.
Revista Brasileira de Saúde MaternoInfantil. Recife (PE), v. 10, Supl. 2, p. 297302, 2010.

ROZA, B. A. et al. Doação de órgãos e tecidos: relação com o corpo em nossa sociedade. Acta Paulista de Enfermagem. São Paulo (SP), v. 23, n. 3, p. 417-422, 2010.

SANTOS, A. L. Direitos e dúvidas postos pelas decisões de tratar e de não tratar. In: Bem da pessoa e bem comum: um desafio à bioética. Centro de Estudo de Bioética (CEB): Coimbra; 1998.

SANTOS, M. J.; MASSAROLLO, M. C. K. B. Processo de doação de órgãos: percepção de familiares de doadores cadáveres. Revista Latino-Americana de Enfermagem. São Paulo (SP), v. 13, n. 3, p. 382-387, 2005. 